\title{
ENTREVISTA
}

\section{EDUCAÇÃO JÁ!}

Encarar a educação brasileira como a solução para os profundos déficits de desenvolvimento do país demanda a articulação das mais diversas esferas econômicas em prol de um ensino de qualidade. Esta é a proposta de Priscila Cruz, que nesta entrevista exclusiva para o Boletim Técnico do Senac, fala da iniciativa suprapartidária Educação Já! Lançada neste ano eleitoral, é uma ação que pretende obter o compromisso dos futuros governantes para um projeto educacional que atenda às reais necessidades do Brasil.

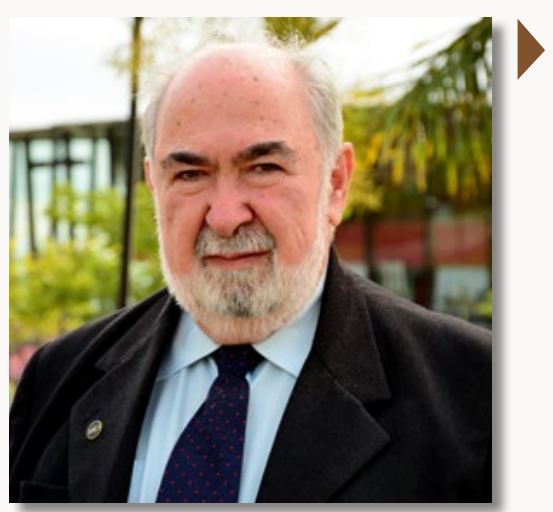

Francisco Aparecido Cordão

Especialista em Educação Profissional, Diretor da Peabiru Educacional e Titular da Cadeira 28 na Academia Paulista de Educação.

E-mail: facordao@uol.com.br

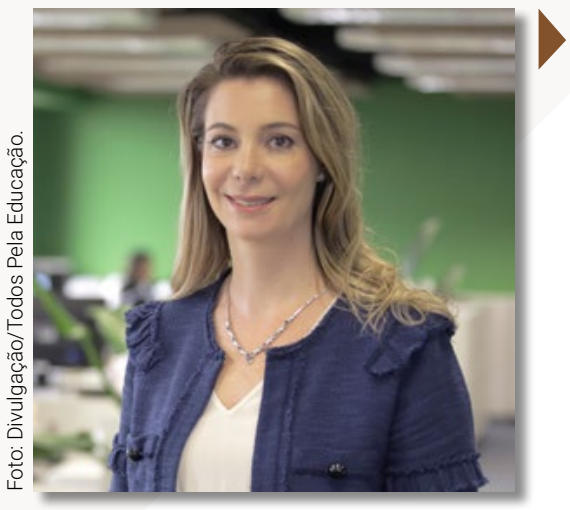

\section{Priscila Cruz}

Mestre em Administração Pública pela Harvard Kennedy School (EUA), Cofundadora e

Presidente-executiva do movimento

Todos Pela Educação.

E-mail: priscila@todospelaeducacao.org.br 
FAC- Em um país como o Brasil, em que uma das faces mais nefastas é a desigualdade social, a falta de estratégia no apoio à Educação atinge com mais dureza os estudantes em situação de maior vulnerabilidade. Como mudar esse quadro?

PC- Mudar essa rota não é um problema nem de professores, nem de familiares, nem de alunos, nem de gestores educacionais individualmente, mas de toda a sociedade brasileira. A situação exige um ataque estratégico, um esforço combinado e inteligente de vários setores e atores da Educação, para criar uma rede de políticas públicas que se influenciem mutuamente, reforçando as características positivas umas das outras.

FAC- A iniciativa Educação Já! reflete esse esforço combinado, esse ataque estratégico para dar um salto qualitativo na Educação Nacional nos próximos anos?

PC- Educação Já! é uma iniciativa suprapartidária liderada pelo movimento Todos Pela Educação e formada por um grupo plural de especialistas, movimentos e instituições. Guiados pela pergunta "O que devemos fazer para dar um salto qualitativo na Educação nos próximos anos?", o grupo aponta prioridades que podem impulsionar a Educação brasileira nos próximos quatro anos de gestão (2019-2022), como uma base nacional de aprendizagem, alfabetização, ensino médio, professores, governança e gestão e, por fim, financiamento. A sinergia entre essas ações combinadas pode alterar as trajetórias escolares e de vida de milhares de brasileiros.

A ideia é que, na hora de estabelecer planos para a Educação, o próximo Presidente da República e os governantes estaduais levem em conta tais propostas e compreendam que uma política pública de Educação concebida isoladamente tem efeito limitado, mas, em conjunto, é possível transformar o país. A insistência na ideia do conjunto não é insignificante, pois ações combinadas podem desencadear um círculo virtuoso, em que uma ação apoia as demais.

Diagnosticar com qualidade os desafios e elaborar políticas públicas com base em evidências e experiências exitosas pode ser a chave para que, em um curto espaço de tempo, o ensino brasileiro retome o pulso necessário para o seu efetivo desenvolvimento.

\section{FAC- Como essa iniciativa conversa com o Plano Nacional de Educação?}

PC- O Plano Nacional de Educação (PNE) é um marco para a Educação do país, mas ainda precisa de uma estratégia de execução para vencer os atuais atrasos no cumprimento de suas metas - hoje, conforme um levantamento do Ministério da Educação (MEC), apenas uma das ações foi cumprida. Tirar o plano do papel, portanto, exigirá de nossos próximos governantes uma visão de curto e médio prazo que dê atenção à continuidade das políticas públicas em Educação, considerando a Educação como a grande prioridade nacional. 
FAC- Ainda há muito a se fazer para criar um leque de políticas públicas bem amarradas, especialmente no que diz respeito aos nossos professores?

PC- Ao olharmos para o cenário brasileiro, percebemos que poucos aventuram-se a seguir a carreira docente: apenas 15,4\% dos jovens do Ensino Médio dão resposta afirmativa a esse questionamento, conforme apontou levantamento do Todos Pela Educação. Além disso, os que escolhem dar aulas enfrentam muitos desestímulos. Segundo o Censo Escolar, 46\% dos professores do Ensino Fundamental e Médio lecionam disciplinas para as quais não foram formados.

O Brasil que queremos é um Brasil em que ser professor seja sinônimo de justo orgulho. Esse profissional deve estar no centro das políticas públicas para a área educacional e o motivo é muito simples: sem ele, qualquer avanço é limitado. É justamente o acúmulo de dificuldades desse profissional que explica, em parte, o preocupante quadro atual de nossa Educação. Se o objetivo da Educação é formar alunos transformadores do espaço e do mundo, o professor é o coração dessa missão, atuando como mediador entre as potencialidades dos estudantes e as habilidades necessárias para a autonomia crítica.

Diante disso, iniciativas que ressignifiquem o que é ser professor no Brasil não podem mais ser adiadas. Além de melhorarmos a remuneração dos docentes, é preciso investir em ações que favoreçam a profissionalização e a valorização social da carreira, como a criação de referências básicas para a atuação desses profissionais e a reformulação dos cursos destinados tanto à sua formação inicial quanto continuada, trazendo o dia a dia da escola para dentro dos cursos de Pedagogia e demais licenciaturas, para ficarmos apenas em duas políticas essenciais.

FAC- A formação docente também é um desafio com a efetiva implantação da Base Nacional Comum Curricular (BNCC), recentemente aprovada pelo CNE e devidamente homologada pelo MEC. Qual é o papel da BNCC dentro de uma visão de políticas estruturantes de Educação para o país?

PC- A aprovação da BNCC da Educação Infantil e do Ensino Fundamental são tópicos essenciais que precisam de prosseguimento. Se quisermos transformar o futuro da escola e, no processo, o futuro do próprio país, essa mudança precisa enfrentar a crise de aprendizagem em que vivemos. Dito de outra maneira, é urgente aprimorar o tempo de ensino-aprendizagem dentro das salas de aula. Ao contrário de ser a causa dos problemas, os alunos que não aprendem são, na verdade, uma das consequências perversas de um sistema de ensino que há muito não tem conseguido cumprir seu dever. A BNCC pode colaborar para mudar significativamente esse quadro ainda desfavorável.

O documento aprovado deve guiar - e não engessar - mais de 5 mil escolas e redes de ensino na elaboração e adaptação de saberes mínimos para crianças de todo o país. A BNCC é uma oportunidade valiosa para que as redes e escolas discutam o quê, como e para que seus alunos aprendem. Além disso, o texto apresentado 
representa uma efetiva chance de potencializar a atuação dos educadores que passarão a ter um referencial para guiar seus ensinamentos em classe. Em se tratando da Educação Infantil, por exemplo, esse é um acontecimento inédito em nossa República Federativa.

\section{FAC- Você entende que a Educação Infantil é ponto fundamental para melhorarmos a qualidade das etapas posteriores da Educação Básica?}

PC- Para alterarmos o final de uma rota, é preciso ajustá-la ainda no começo. Em matéria de Educação também é assim que acontece. Os déficits de aprendizagem são obstáculos impostos aos estudantes desde os anos iniciais e que reverberam lá no fim da Educação Básica. Não adianta tentar estancar as dificuldades apenas no final dessa etapa educativa. É necessário, acima de tudo, preveni-las ainda na Primeira Infância (de 0 a 5 anos) e também no processo de alfabetização, a partir dos 6 anos.

Essas fases iniciais representam a base de todo o restante de saberes que serão apresentados em toda a educação formal ao longo da vida. O planejamento e a execução para a Educação dos próximos nove anos de Ensino Fundamental e três anos de Ensino Médio, para a conclusão da Educação Básica, devem começar, literalmente, no berço. As ações para essas áreas devem ser capazes de identificar as populações de crianças mais vulneráveis e suas necessidades, para propor soluções intersetoriais, que garantam efetivamente a sua aprendizagem. Quanto mais cedo as desigualdades forem combatidas, mais amplas serão as reais oportunidades de desenvolvimento democrático e menores os núcleos de privilegiados.

Esse último ponto, aliás, está ligado a um desafio transversal que deve estar no horizonte de todos os que pensam Educação no Brasil: a falta de equidade. Em todo o país e em todas as etapas de ensino, nossos alunos não estão recebendo as mesmas chances de aprender e, mais grave ainda é que, ao aprender, não desenvolvem sua capacidade de continuar aprendendo ao longo da vida.

Independentemente da área em que se queira avançar na Educação Nacional, os desafios socioeconômicos permanecem diferenciando pobres e ricos. Para se ter uma ideia, no $3^{\circ}$ ano do Ensino Fundamental, os alunos de famílias de nível socioeconômico muito baixo têm índice de alfabetização adequada cinco vezes menor do que os de famílias no extremo oposto. Essa diferença chega à vergonhosa marca de 22 vezes maior, quando observada no $9^{\circ}$ ano do Ensino Fundamental. Essa situação nacional precisa ser urgentemente alterada.

FAC- Para que o país consiga alcançar esse conjunto de políticas públicas articuladas, qual é a importância da governança de um Sistema Nacional de Educação?

PC- Nossos futuros gestores precisam atuar em regime de colaboração entre as diversas instâncias federativas, operando um efetivo Sistema Nacional de Educação. E precisam concretizar isso o quanto antes. O projeto Educação Já aponta a 
necessidade de um esquema inteligente, tático, que combine diferentes políticas educacionais. Não basta apoiar só a Base Nacional Comum Curricular, também é preciso criar incentivos para o professor; entretanto, não é suficiente apoiar apenas os docentes, mas impulsionar a alfabetização, e assim por diante. De maneira mais concreta, uma verdadeira rede de execução dessas ideias também precisa ser estabelecida. Trata-se de uma rede de segurança para nossa Educação; uma espécie de pano de fundo, em que Governo Federal, governos estaduais e prefeituras contem com regras claras de como apoiarem-se mutuamente..

Saber a quem recorrer financeira e administrativamente é um dos fatores invisíveis que fazem toda a diferença na atuação das redes de ensino e pode determinar mudanças efetivas dentro das próprias salas de aula. À primeira vista, o esforço a curto prazo pode parecer grande, mas será recompensado sobejamente com os frutos sociais a serem colhidos por inúmeras gerações de cidadãos brasileiros. A Educação pode não resolver todos os nossos problemas, mas certamente é parte de todas as soluções possíveis, e cabe aos nossos representantes levar a cabo esta que é a vontade de todos, ter Educação Já!

FAC- 0 projeto Educação Já! tem em sua agenda ações que visam promover a qualidade da Educação Profissional?

PC- A escola precisa ser mais atraente para os nossos jovens. Nesse sentido, uma das diretrizes do documento da iniciativa Educação Já! está centrada na reorganização dos conteúdos escolares do Ensino Médio, de modo que as juventudes se enxerguem na escola. Isso inclui pensar opções para os jovens que têm interesse em se preparar para a vida profissional. O Educação Já! propõe que o Governo Federal fortaleça a oferta da Educação Profissional com articulações e parcerias e também fomente a melhora da qualidade dos cursos e a relação do jovem com o mercado de trabalho.

Também é essencial que a União crie mecanismos efetivos de expansão da oferta do itinerário profissionalizante, previsto na chamada Reforma do Ensino Médio. A modalidade tem de ser de qualidade e espelhar as demandas regionais. O Governo Federal terá de apoiar as redes estaduais e estimular parcerias para garantir a implementação efetiva do que foi proposto.

FAC- No Brasil, os programas de aprendizagem são uma das principais portas de entrada de estudantes no mundo do trabalho e, recentemente, foi lançada a Portaria n. 634, de 9 de agosto de 2018, que visa dar novas diretrizes ao Cadastro Nacional de Aprendizagem Profissional (CNAP). Como o Educação Já! avalia os itinerários formativos dos cursos de aprendizagem hoje? Estão de acordo com a realidade atual dos jovens e dos empregadores?

PC- Com respeito à Portaria 634, é necessário que se cumpra a avaliação e fiscalização das entidades formadoras para garantir um Ensino Profissional de qualidade e que, de fato, ofereça uma formação alinhada às expectativas dos jovens e suas regiões. 
E os próprios jovens demandam educação profissional. Em pesquisa realizada pelo Todos pela Educação, 78\% dos jovens responderam que consideram muito importantes matérias dirigidas a formação profissional, técnica e aconselhamento; e que $76 \%$ dos alunos do ensino médio afirmam estar dispostos a trocar um terço das disciplinas comuns por técnicas. Diante disso, independentemente do curso, a demanda por uma opção de formação profissional é real e precisa estar disponível. Além disso, os cursos formativos devem sempre aliar conhecimentos práticos aos teóricos, e jamais prejudicar a aprendizagem na escola regular.

\section{FAC- Como o Educação Já! pretende encontrar soluções para as necessidades mais prementes da juventude brasileira atual, como segurança e emprego?}

PC- Há uma retroalimentação positiva entre Educação e as demais áreas, como muitas pesquisas mostram. Se quisermos dar um salto de qualidade na Educação, precisaremos do apoio das pastas de saúde, segurança e cultura, para citar apenas algumas. O contrário também é verdadeiro: para chegarmos a uma sociedade em que nossos jovens vivam mais e melhor, capazes de atingir seus sonhos, será necessário investir em Educação.

Estudos já comprovaram que quanto maior a escolaridade de uma população, maior a sua produtividade, proporcionando um maior leque de opções no mercado de trabalho e melhores condições ao longo da vida. Dados do Cadastro Nacional de Desempregado (Caged) também mostram que as pessoas com menor escolaridade têm mais dificuldade de se empregar.

Quanto à segurança de nossos jovens, o Educação Já! aponta para a importância de se ampliar as oportunidades educacionais. Quanto mais igualitária for a nossa Educação, mais bem distribuídas serão as oportunidades de desenvolvimento para todas as juventudes, independentemente da situação socioeconômica. Para isso, defendemos a ampliação de vagas de Ensino em Tempo Integral, especialmente para os jovens que vivem em regiões de maior vulnerabilidade. Mas só isso não basta. É fundamental que nossas escolas sejam orientadas por uma cultura de paz, que previna a criminalidade. As diversas áreas do Estado devem trabalhar em conjunto para garantir que todo aluno frequente a escola em segurança e aprenda valores de tolerância e diversidade.

\section{FAC- Que movimentos sociais estão apoiando o Educação Já!?}

PC-Diversas instituições e muitas pessoas físicas ligadas a diferentes pautas educacionais já contribuíram com o documento Educação Já! Participaram da construção coletiva da iniciativa professores, gestores públicos, pesquisadores, especialistas de áreas diversas (como saúde e primeira infância), profissionais do ramo das comunicações, empresários, organizações do terceiro setor. Mais aqui: https://www.todospelaeducacao.org.br/pag/iniciativa-educacao-ja. 